\title{
RANCANG BANGUN INSTRUMEN PENGUKUR SUHU DAN KELEMBAPAN UDARA MENGGUNAKAN DT-SENSE SHT11
}

\author{
Imam Hidayat ${ }^{1}$, Hesky Stevy Kolibu ${ }^{1)}$, Slamet Suyitno Raharjo ${ }^{2)}$ \\ 1) Jurusan Fisika, FMIPA UNSRAT, Manado \\ ${ }^{2)}$ Pusat Gempa Regional X BMKG, Manado \\ e-mail: mamhid89@gmail.com; heskystevy@yahoo.com; stageof.winangun@bmkg.go.id
}

\begin{abstract}
ABSTRAK
Telah dilakukan pembuatan instumen pengukur suhu dan kelembapan udara menggunakan sensor DT-Sense SHT11 dan modul mikrokontroler DT-AVR Low Cost Micro System. Kemudian instrumen diuji dengan alat ukur standar. Pengujian dilakukan mulai bulan Juni 2013 dan berakhir bulan Oktober 2013di Laboratorium Fisika, Fakultas Matematika dan Ilmu Pengetahuan Alam, Universitas Sam Ratulangi Manado dan pengujian lapangan dilakukan di Stasiun Meteorologi Kelas II Maritim Bitung. Hasil pengujian dianalisis dengan metode grafik, analisis Korelasi dan Uji t sampel berpasangan. Hasilnya berhasil dibuat dengan ketelitian pengukuran hingga $0,01^{\circ} \mathrm{C}$ untuk pengukuran suhu udara dan $0,0001 \%$ untuk pengukuran kelembapan udara. Terdapat selisih antara instrumen yang dibuat dengan alat ukur standar. Rata-rata $1,4{ }^{\circ} \mathrm{C}$ untuk suhu udara dan $3 \%$ untuk kelembapan relatif.
\end{abstract}

Kata kunci: sensor, mokrokontroler, SHT11

\section{DESIGN AND BUILD OF AIR TEMPERATURE AND HUMIDITY MEASUREMENT INSTRUMENT USING DT-SENSE SHT11}

\begin{abstract}
Have been made a temperature and humidity measurement instrument using DT-Sense sensor SHT11 and microcontroller modules DT-AVR Low Cost Micro System. Then the instrument was tested with standard measurement tools. The tests were conducted starting in June 2013 and ended in October 2013 at the Laboratory of Physics, Faculty of Mathematics and Natural Sciences, Sam Ratulangi University and field trials conducted in Class II Meteorological Station Maritime Bitung. The test results were analyzed by graphical method, correlation analysis and paired sample $\mathrm{t}$ test. The result of measurement accuracy up to $0,01^{\circ} \mathrm{C}$ for measuring air temperature and up to $0,0001 \%$ for air humidity measuring. The difference between the instruments are made with standard measurement tools. An average of $1.4^{\circ} \mathrm{C}$ for temperature and $3 \%$ for relative humidity.
\end{abstract}

Keywords: sensor, microcontroller, SHT11

\section{PENDAHULUAN}

Keadaan cuaca adalah fenomena alam yang terdiri dari berbagai proses fisis yang menyertainya. Di dalam mempelajari fenomena cuaca perlu diketahui unsur unsur cuaca. Pada stasiun pengamatan cuaca, unsur - unsur cuaca yang diamati antara lain suhu dan kelembapanudara relatif. Kelembaban relatif dan suhu udara adalah parameter yang penting dalam pengukuranmeteorologi. Kelembaban relatif menggambarkan rasio uap air yang terdapat dalam campuran udara-air dalam fasa gas pada suhu udara tertentu, sedangkan suhu udara yaitu jumlah panas yang terkandung di udara ( Tjasyono, 2004).

Pengembangan instrumentasi digital semakin canggih dari waktu ke waktu. Pengembangan sensor berbasis semikonduktor yang terkalibrasi dan memiliki akurasi tinggi semakin mudah didapat. Pengembangan sebuah instrumen untuk mengukur kelembaban relatif dan suhu udara sangat diperlukan, sehingga dalam penelitian ini dibuat suatu alat ukur suhu dan kelambapan udara otomatis dengan menggunakan modul DT- SENSE SHT11. 
DT - SENSE SHT11 adalah modul sensor yang dapat mengukur suhu dan kelembapan udara yangkemudian hasil pengukuran diverifikasi dengan alat konfensional yang ada di Stasiun Meteorologi untuk mengetahui keakuratannya.

\section{METODE}

\section{Waktu Penelitian}

Penelitian dilakukan mulai bulan Juni 2013 dan berakhir bulan Oktober 2014 di Laboratorium Fisika, Fakultas Matematika dan Ilmu Pengetahuan Alam, Universitas Sam Ratulangi Manado. Pengujian lapangan dilakukan di Stasiun Meteorologi Kelas II Maritim Bitung.

\section{Desain Alat}

Penelitian ini menggunakan desain instrumen sebagai berikut:

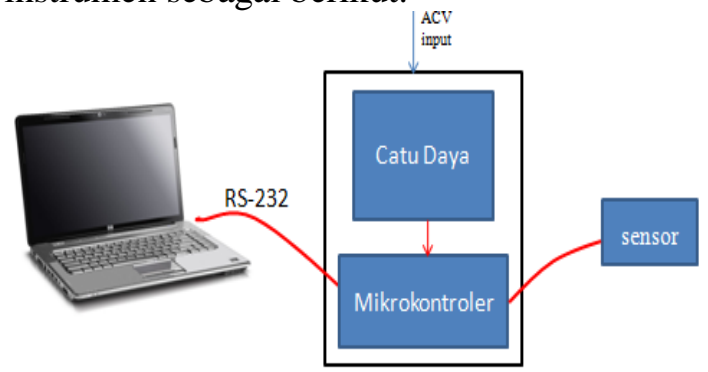

Gambar 1. Desain Instrumen

Perangkat keras alat pengukur suhu dan kelembapan udara ini terbagi menjadi 4 bagian yaitu : (1) Unit komputer personal, (2) Unit mikrokontroler, (3) Unit catu daya dan (4) Unit sensor. Tegangan yang diberikan pada modul mikrokontroler sebesar 9 VDC. Rancangan catu daya tersebut melalui tiga proses yaitu penurunan tegangan, penyearah arus kemudian regulasi tegangan.

Perangkat lunak berkaitan dengan kinerja perangkat keras. Perangkat lunak pada sistem mikrokontroler biasa juga disebut firmware. Dalam penelitian ini program untuk sisi mikrokontroler ditulis dengan bantuan Code Vision AVR dan program pada sisi komputer dibuat menggunakan Borland Delphi 7.0. Firmware mikrokontroleryang telah adadownload ke mikrokontroler menggunakan DT-HiQ AVR USB ISP.

\section{Pengujian}

Pengujian skala lapangan meliputi kinerja instrumen di lapangan dan hasilnya dibandingkan dengan alat ukur yang ada. Alat ukur pembanding yang digunakan berupa termometer bola basah dan termometer bola kering di Stasiun Meteorologi Kelas II Maritim Bitung. Alat diletakan pada tempat yang sama secara berdampingan selama 10x24 jam. Interval yang digunakan untuk pengukuran adalah sebesar 1 jam. Hasil yang didapat oleh instrumen yang dibuat dibandingkan dengan hasil observasi harian BMKG.

\section{Pengolahan Data}

Analisis grafik digunakan untuk memvisualisasikan data. Metode ini menggunakan software Microsoft Excel 2007. Data yang diplot adalah data selisih suhu dan selisih RH tiap jam selama rentang waktu penelitian, kemudian ditarik rataratanya. Data rata-rata tersebut diplot untuk mengetahui besarnya selisih suhu $(\Delta \mathrm{T})$ dan selisih $\mathrm{RH}(\Delta \mathrm{RH})$ antara alat ukur standar dan SHT11.

Analisis korelasi digunakan untuk mengetahui arah dan kekuatan hubungan antara dua variabel, dalam hal ini hubungan antara data pengukuran alat standar dengan instrumen yang diteliti (SHT11). Piranti yang digunakan dalam metode ini adalah MINITAB 14. Ukuran hubungan linear antara dua variabel $\mathrm{X}$ dan $\mathrm{Y}$ dengan koefisien korelasi sampel $r$, yaitu:

$$
r=\frac{n \sum_{i=1}^{n} \mathrm{X}_{i} \mathrm{Y}_{i}-\left(\sum_{i=1}^{n} \mathrm{X}_{i}\right)\left(\sum_{i=1}^{n} \mathrm{Y}_{i}\right)}{\sqrt{\left[n \sum_{i=1}^{n} \mathrm{X}_{i}{ }^{2}-\left(\sum_{i=1}^{n} \mathrm{X}_{i}\right)^{2}\right]\left[n \sum_{i=1}^{n} \mathrm{Y}_{i}-\left(\sum_{i=1}^{n} \mathrm{Y}_{i}\right)^{2}\right]}}
$$

Bila $\mathrm{r}=0$ atau mendekati 0 , maka hubungan antara kedua variabel sangat lemah atau tidak terdapat hubungan sama sekali. Bila $r=1$ atau mendekati 1, maka hubungan antara keduanya sempurna positif atau terdapat hubungan yang sangat kuat. Bila $r=-1$ atau mendekati -1, maka hubungan antara keduanya sempurna negatif atau terdapat hubungan yang sangat kuat negatif. Sedangkan tingkat signifikansi ditetapkan $95 \%$ atau $P=0,05$. Jika p- value lebih kecil dari 0,05 maka dikatakan hubungan kedua variabel signifikan sedangkan jika $\mathrm{p}$ - value lebih besar atau sama dengan 0,05 maka dapat disimpulkan hubungan kedua variabel tidak signifikan 
Paired sample $t$ test yaitu metode pengujian berdasarkan beda dua sampel yang berpasangan dan menentukan apakah hasilnya secara statistik berbeda. Paired sample t-test dirumuskan sebagai berikut:

$$
t=\frac{|| \bar{X}_{d}|-| X_{o}||}{\frac{s_{d}}{\sqrt{n}}}
$$

Dimana:

$$
\begin{aligned}
& \overline{X_{d}}=\text { Selisih data rata-rata } \\
& X_{O}=\text { Nilai selisih yang diharapkan.Biasanya } \\
& \text { benilai } 0 \\
& \mathrm{~S}_{\mathrm{d}}=\text { Standar deviasi dari selisih data } \\
& \mathrm{n}=\text { Jumlah pasangan sampel } \\
& \text { Kesimpulan: }
\end{aligned}
$$

Ho : tidak ada perbedaan antara alat standar dengan SHT11

H1: ada perbedaan antara alat standar dengan SHT11

Ho diterima dan H1 ditolak apabila hasil $t$ hitung lebih kecil dari $t$ tabel sedangkan apabila $t$ hitung lebih besar dari $t$ tabel maka Ho ditolak dan $\mathrm{H} 1$ diterima.

\section{HASIL DAN PEMBAHASAN}

\section{Perakitan Instrumen}

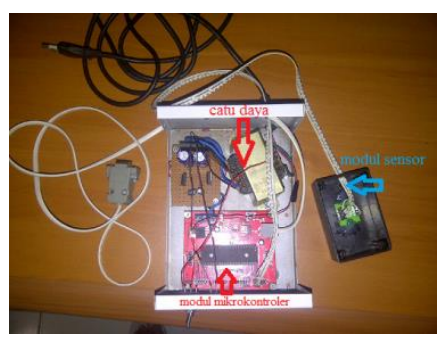

Gambar 2. Integrasi instrumen

Catu daya yang telah dibuat dihubungkan dengan modul mikrokontroler pada $\mathrm{V}$ in. Kabel Vout (+) pada catu daya dihubungkan $\mathrm{ke} \mathrm{V}$ in +9VDC pada modul mikrokontroler. Kabel GND pada catu daya dihubungkan ke GND modul mikrokontroler.Lampu LED indikator akan menyala apabila catu daya telah terhubung dengan benar.

Modul sensor DT-SENSE SHT11 dan modul mikrokontroler DT-AVR Low Cost Micro System dihubungkan dengan kabel jumper. Kabel ini berfungsi untuk komunikasi data antara sensor dan mikrokontroler. Pada sisi modul mikrokontroler port yang digunakan adalah
Port A atau pin J10. Tata letak pin ditunjukkan pada gambar 10 dan pasangan pin antara DT-AVR dan DT-SENSE SHT11 dihubungkan sesuai pada tabel 1

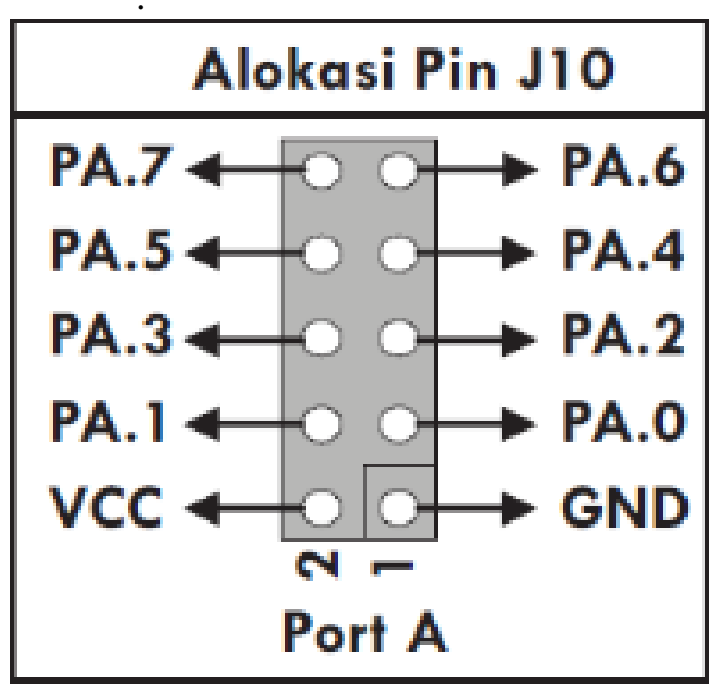

Gambat 3. Alokasi pin J10

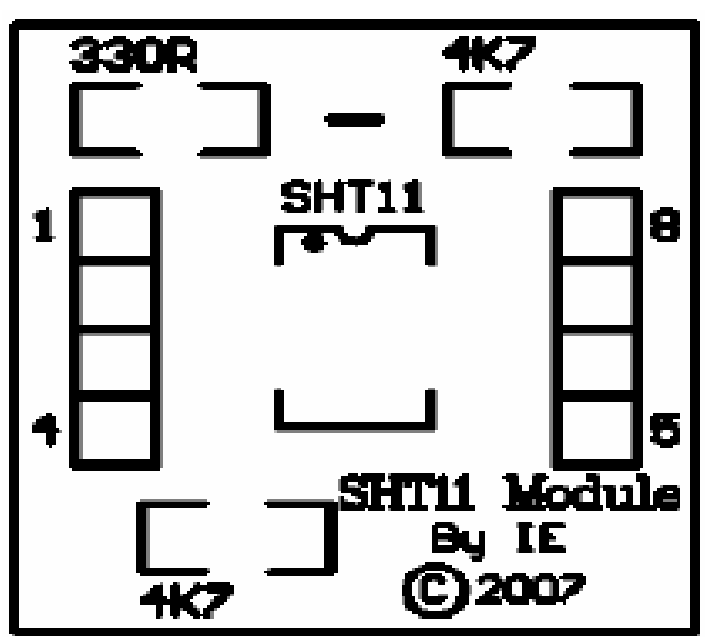

Gambar 4. Alokasi pin SHT11

Tabel 1. Alokasi pin DT-AVR dan DT-Sense SHT11

\begin{tabular}{|c|c|}
\hline $\begin{array}{c}\text { DT-AVR Low Cost Micro } \\
\text { System (J10) }\end{array}$ & DT.SENSE SHT11 Module \\
\hline GND (Pin 1) & Ground (Pin 4) \\
\hline VCC (Pin 2) & +5 VDC (Pin 8) \\
\hline PA.0* (Pin 3) & Data (Pin 1) \\
\hline PA.1* (Pin 4) & Clock (Pin 3) \\
\hline
\end{tabular}

Pembuatan firmware dilakukan menggunakan CVAVR (Code Vision AVR). Kode pemrograman kemudian dikompilasi. Setelah kompilasi, akan terbentuk file dengan ekstensi .hex. Firmware yang telahterbentuk, 
kemudian diunduh ke dalam mikrokontroler Atmega8535 menggunakan kabel data DTHIQ AVR USB ISP.

Pada komputer program tampilan data dibuat menggunakan bantuan Borland Delphi 7.0. Bahasa yang digunakan pada Delphi adalah bahasa pemrograman Pascal.Pada pemrograman ini dilakukan konversi suhu dan kelembapan udara dari sinyal yang dikirim oleh mikrokontroler. Kode yang telah benar seluruhnya dikompilasidengan menekan CTRL + F9. File program hasil kompilasi akan terbentuk pada folder di mana diletakkan Delphi Project dengan ekstensi .exe.

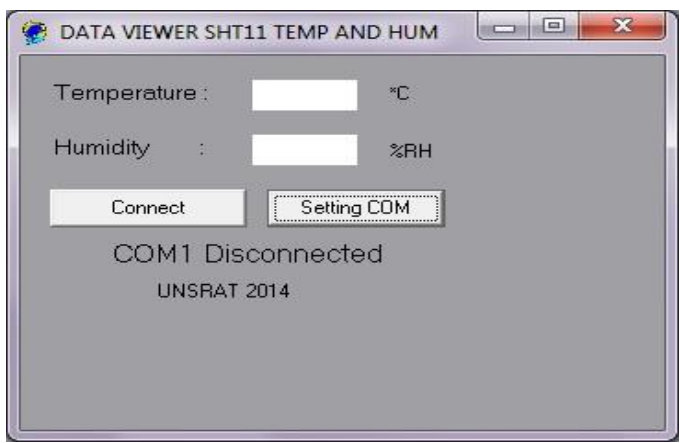

Gambar 5. Tampilan program.

\section{Pengujian}

Pengujian lapangan dilakukan di Stasiun Meteorologi Kelas II Maritim Bitung. Modul sensor SHT11 diletakan dalam sangkar meteorologi berdampingan dengan termometer bola basah dan termometer bola kering sedangkan modul mikrokontroler dan komputer display data diletakkan di bawah sangkar. Interval pengambilan data perjam, bersamaan dengan pembacaan termometer bola kering dan termometer bola basah pada waktu jam pengamatan.

\section{Suhu Udara}

Hasil pengukuran suhu udara antara sensor SHT11 dan termometer memiliki garis tren yang mirip dengan data pengukuran dengan termometer konvensional, namunnilainya berbeda dengan data termometer. Terdapat selisih antara data hasil pembacaan sensor SHT11dengan hasil pembacaan thermometerrange selisihnya antara $1,2{ }^{\circ} \mathrm{C}$ hingga $1,5{ }^{\circ} \mathrm{C}$ dengan rata-rata $1,38^{\circ} \mathrm{C}$

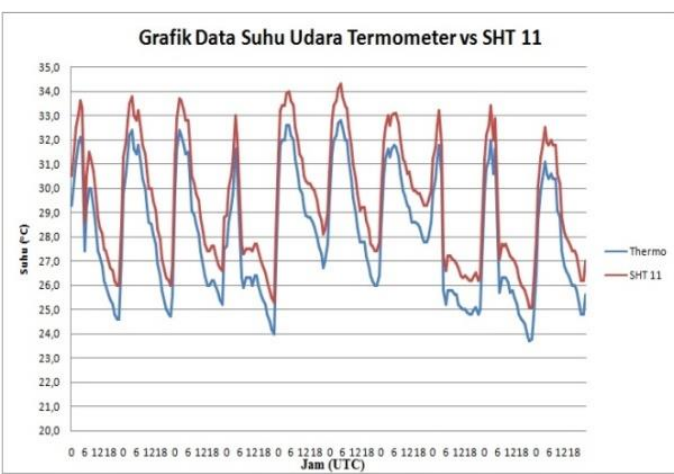

Gambar 6. Grafik data suhu udara termometer versus SHT11

Analisis menggunakan korelasi didapat nilai $r$ sebesar 1,000 dan $P$ - value sebesar 0,000 . Analisis tersebut mengindikasikan hubungan antara data suhu dari SHT11 dan termometer sangat tinggi dan keduanya dikatakan signifikan, karena $P$ value nya $<0,05$.

Uji t tersebut, didapat perhitungan $t$ statistik sebesar -307.55 . Nilai ini jauh lebih kecil dari nilai $\mathrm{t}$ tabel dengan $\alpha=0,05$ dan df = 240 sebesar 1,6512, oleh karena itu dapat disimpulkan Ho diterima atau tidak ada perbedaan hasil pengukuran.

\section{Kelembapan Udara}

Pengukuran kelembapan udara antara sensor SHT11 dan termometer dapat dilihat pada gambar. Berdasarkan tampilan gambar bisa dilihat bahwa hasil pengukuran SHT11 memiliki garis tren yang mirip dengan data pengukuran dengan alat ukur standar. Selisih kelembapannya tidak konstan di tiap-tiap jam dengan selisih yakni berkisar antara $2 \%$ hingga 5\%, selisih rata-rata 3,3\%.

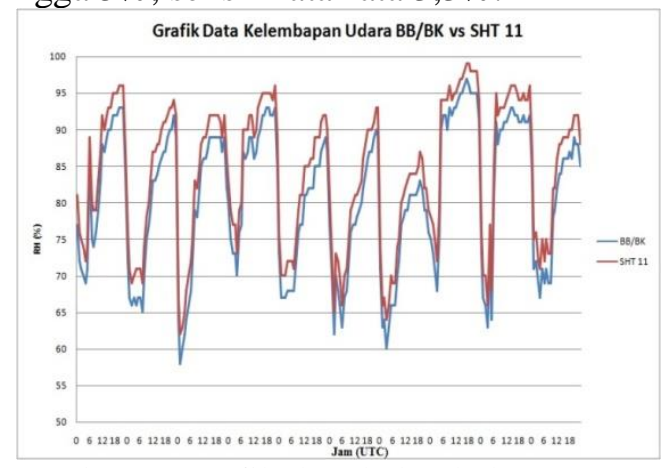

Gambar 7. Grafik data kelembaban BB/BK versus SHT11

Analisis korelasinya didapat nilai $r$ sebesar 0,998 dan $P$ - value sebesar 0,000 yang berarti bahwa antara data kelembapan 
dari SHT11 dan alat ukur standar mempunyai hubungan yang sangat tinggi. Hubungan keduanya juga dikatakan signifikan karena $P$ value nya $<0,05$.

Analisis uji $t$ didapat nilai perhitungan $t$ statistik sebesar $-81,90$ jauh lebih kecil dari nilai $t$ tabel dengan $\alpha=0,05$ disimpulkan Ho diterima atau tidak ada perbedaan hasil pengukuran.

\section{KESIMPULAN}

1. Telah dibuat instrumen pengukur suhu udara dan kelembapan udara relatif dengan menggunakan sensor DTSENSE SHT11 dan mikrokontroler DTAVR Low Cost Micro System dengan ketelitian maksimum $0,01^{\circ} \mathrm{C}$ untuk suhu udara dan $0,0001 \%$ untuk kelembapan udara relatif.

2. Dari pengujian instrumen di Stasiun Meteorologi menujukkan performa yang baik.

3. Tedapat selisih rata-rata $+1,4^{\circ} \mathrm{C}$ untuk suhu udara dan $+3 \%$ untuk kelembapan udara relatif.

\section{DAFTAR PUSTAKA}

Atmel. 2008. 8-bit AVR® Microcontroller with 32 KB In-System Programmable Flash.

http://www.atmel.com/dyn/resources/ prod_documents/doc2503.pdf.

[21September 2013]

Sensirion. 2007. SHT1x/SHT7x Humidity and

Temperature Sensor.

http://www.sensirion.com/images/get

File?id=25. [31 Juli 2013]

Soepangkat. 1994. Pengantar Meteorologi. Badan Diklat Meteorologi dan Geofisika, Jakarta.

Tjasyono, B. 2004. Klimatologi. ITB: Bandung.

Walpole, Ronald E.,Myers, Raymond H. 1995. Ilmu Peluang dan Statistika Untuk Insinyur dan Ilmuwan. ITB, Bandung.

Wiyono, Didik., S. T. 2007. Panduan Praktis Mikrokontroler Keluarga AVR Menggunakan DT-Combo AVR 51 Starter Kit dan DT-Combo AVR Exercise. Innovative Electronics, Surabaya. 